
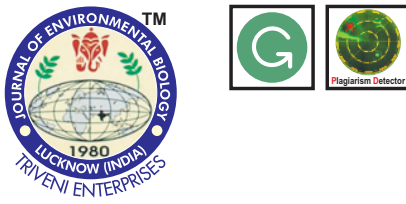

DOI : http://doi.org/10.22438/jeb/38/5(SI)/GM-06
Journal of Environmental Biology

ISSN: 0254-8704 (Print) ISSN: 2394-0379 (Online) CODEN: JEBIDP

\title{
The relationships between beta plant diversity and climatic variables: A case study from Kuyucak mountain district
}

\section{Authors Info}

\section{M.G. Negiz ${ }^{1 *}$ and K. Özkan}

${ }^{1}$ Forestry Department, Sütçüler Vocational School, Suleyman Demirel University, Sütçüler, Isparta, 32260, Turkey

${ }^{2}$ Department of Forest Engineering, Faculty of Forestry, Suleyman Demirel University, Division of Soil Science and Ecology, Isparta, 32100, Turkey

${ }^{*}$ Corresponding Author Email : mehmetnegiz@sdu.edu.tr

Key words

Beta plant diversity,

Biodiversity components,

Mediterranean region,

Environmental factors,

Kuyucak mountain

Publication Info

Paper received : 30.07 .2017

Revised received : 11.06 .2017

Accepted : 26.06.2017

\section{Abstract}

Aim: There are three types of biodiversity, i.e., alpha diversity (diversty within an individual habitat orecosystem), beta diversity (between habitat or ecosystem) diversity between areas) and gamma diversity (total diversity). Alpha diversity indices have been frequently used to examine the relationships between biodiversity and environmental factors. However, studies concerning the relationships between beta diversity and environmental factors are few despite the fact that beta diversity gives more information about ecosystem stability against internal and external threatening factors. The present study was carried out to examine beta plant diversity and climatic factors in Kuyucak Mountain District of the Mediterranean region.

Methodology: Bioclimatic data was obtained from www.wordclimdata.org for the district. Bioclimatic variables having cell size $752 \times 752 \mathrm{~m}$ were storied in the GIS. Four sample plots were taken in each selected cell by controlling from GIS. Coverage values of plant species were recorded in the sample plots. After field survey, beta plant diversities of the cells were calculated by using Whittaker Beta Index ( $\beta w$ ). Next, regression analysis was applied to show the relationship between beta diversity and bioclim variables.

Results: Beta diversity showed positive linear relationship with $\mathrm{BIO1}$ $\mathrm{BIO} 2, \mathrm{BIO}, \mathrm{BIO}$, $\mathrm{BIO}$, $\mathrm{BIO9,} \mathrm{BIO10}$ and $\mathrm{BIO15}$, while it had negatively linear relationships with $\mathrm{BIO4}$, BI011, BI012, BIO14, $\mathrm{BIO17}$ and $\mathrm{BIO18}$

Interpretation: Further studies can be conducted about the other climatic variable in the region, as well as the other environmental variables in order to associate with beta diversity. Thus, potential distribution areas of the plant species and biodiversity components can be identified and mapped with the help of base maps for the area's habitat variables.

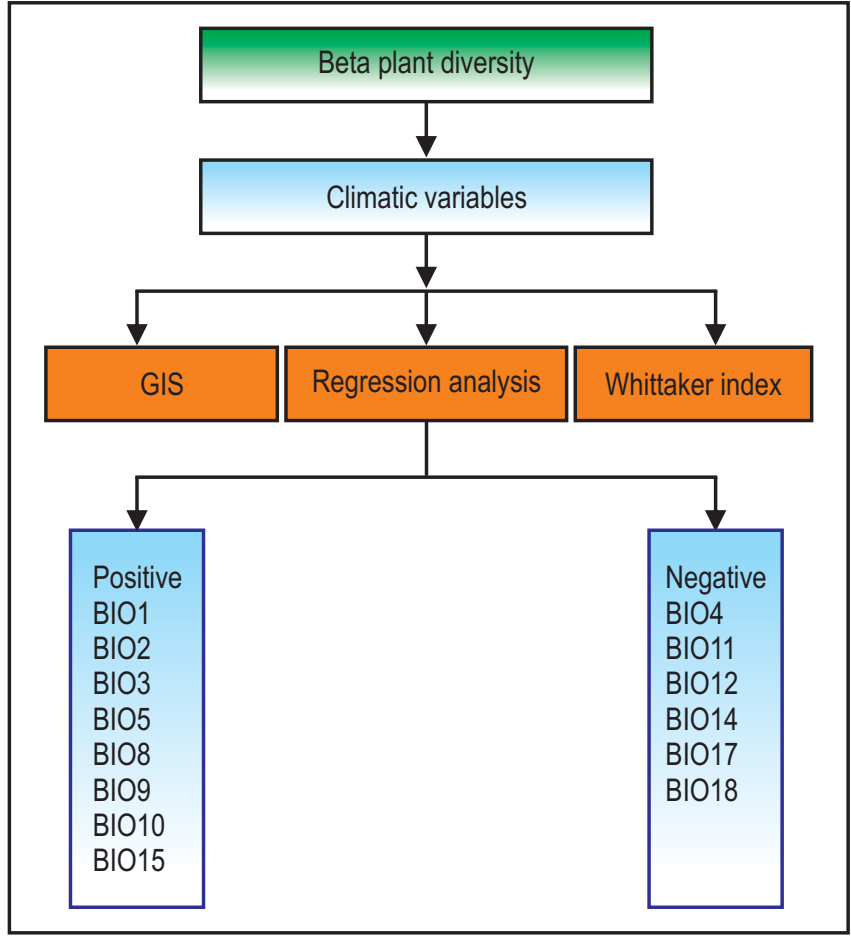




\section{Introduction}

Biodiversity means variation among living organisms from all sources, whereas terrestrial, marine and other aquatic ecosystems, and the ecological structures are part of these ecosystems (Thompson et al., 2009). Biodiversity, a significant research topic in recent years, includes species diversity, ecosystem diversity and genetic diversity, and signifies the continuity, development and future of ecosystems (Hunter, 1996; Pausas and Austin, 2001; Kaya, 2003).

Biodiversity in forest ecosystems is considered at three different levels, i.e., species diversity, functional diversity and structural diversity. In forest ecology, most of the studies focus mainly on plant species diversity (Özkan, 2006; Özkan and Süel 2008; Işık and Uğurlu, 2011). Plant species diversity is divided in three types, via; alpha (within an individual habitat orecosystem), beta (between habitat or ecosystem) and gamma diversity (total diversity) (Whittaker, 1972; Zhao et al., 2005; Marenoet al., 2006; Hashemi, 2010).

High alpha diversity in different parts of an ecosystem does not necessarily mean high diversity in the ecosystem. In this case, it is significant to know more about beta diversity, usually using Whittaker's $\beta w$ index (Özkan, 2010; Özkan and Gülsoy, 2010). In gamma diversity, on the other hand, analyses are conducted after the calculation of alpha and beta diversity figures.

Alpha diversity index is usually selected as dependent variable for analyzing the correlation between biodiversity and habitat features. Beta diversity provides more comprehensive information about the resistance and resilience capacity of an ecosystem against internal and external threats when compared with alpha diversity. The number of studies that focus on the correlation between beta diversity and environmental factors is however quite low.

Correlations between species diversity in forest ecosystems and habitat characteristics have been identified (Linder, 2001; Özkan 2006). Information about these correlations is quite significant in terms of identifying areas which have high value in terms of species diversity regarding the potential species diversity.

Climate variables of the habitat (average temperature, annual precipitation, etc.) are extremely important factors for distribution of plant species. Potential distribution area of many plant species can be identified by conducting studies on climate variables. Thus, important steps can be taken on practices related to diversity.

The present study was conducted with the purpose of determining the correlation between beta plant diversity in Kuyucak Mountain Region, which is located in the high density forest area in the Mediterranean Region and climatic characteristics. As a result of this study, important areas regarding the effects of climate variables on beta plant diversity and species diversity can possibly be identified.

\section{Materials and Methods}

Study area : This study was conducted in Kuyucak Mountain District which is located within the borders of Sütçüler district in Isparta. The study area is located in $30^{\circ} 47$ ' $49^{\prime}$ - $31^{\circ} 20$ '42' E longitude, $37^{\circ} 18$ ' $10^{\prime}$ - $37^{\circ} 43$ '48' N latitude, and covers 128000 ha. The altitude of the region varies between $200 \mathrm{~m}$ and $2500 \mathrm{~m}$ (Fig. 1). Mediterranean influence across the Kovada Canal leads to the prevalence of typical Mediterranean climate throughout the region. According to the nearest weather station data, the average annual temperature in the region is $13.1^{\circ} \mathrm{C}$; the hottest months are July and August with $23.8^{\circ} \mathrm{C}$, and the coldest month is January with $3.3^{\circ} \mathrm{C}$. The average annual total rainfall is 950.1 $\mathrm{mm}$. $(35.7 \%$ (339.3 mm) in winter (January-February-March), $20.9 \%$ (198.6 mm) in spring (April-May-June), 5.4\% in summer (July-August-September) and $38 \%$ in autumn (OctoberNovember-December)). The average relative humidity of the region is $54 \%$, whereas the average annual wind speed is $1.3 \mathrm{~m}$ $\sec ^{-1}$ (DMi, 2012).

The study area is rich in plant species. Özçelik and Korkmaz (2012) identified approximately 63 families and 225

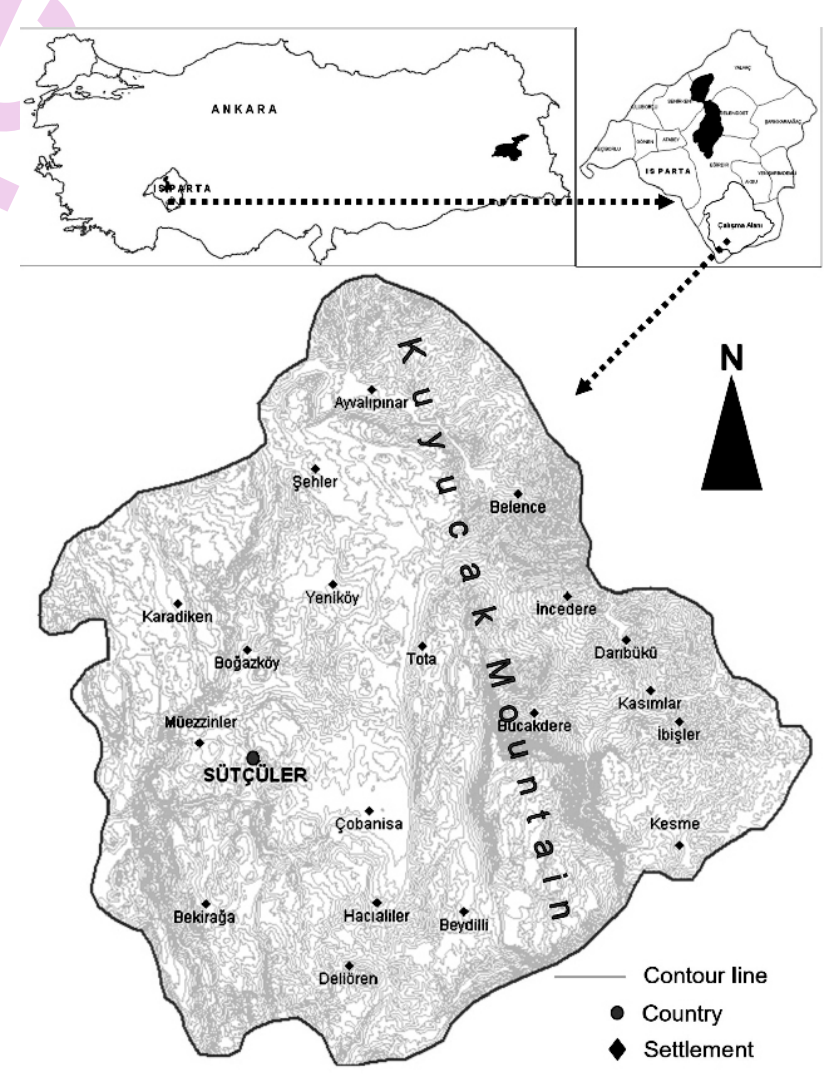

Fig. 1 : Map showing the location of study area 
species making up to 478 species in Sütçüler Districtin Kuyucak Mountain District. Almost all woody vegetation that covers higher parts and the lower part of the Mediterranean Region is naturally found in Kuyucak Mountain District. Therefore, Kuyucak district is a small model of the Mediterranean region, which is the reason we have selected this region as the study area for this research.

The study first conducted expeditions in order to identify sample areas and then under lookland inventory work in the laboratory. For specifying dimensional values and limits of the sample fields, data related to climatic variables generated by Hijmanet al. (2005), available on www.worldclim.org, was used. These variables were firstly cropped using Global Mapper 11 based on Turkey's borders and then were again registered geometrically. As a result of this, the cell size of the variables was fixed as $0.60 \mathrm{~km}^{2}(\sim 0.752 \times \sim 0.752 \mathrm{~km})$. Nineteen climate variables (Bio1-19) and their codes are shown in Table 1.

Four sub-sampling areas each $20 \times 20 \mathrm{~m}$ in size, were taken from each of 800 sample fields (Fig. 2). Coverage values of woody species in 800 sampling sites in total were noted down according to Braun-Blanquet method $(r,+, 1,2,3,4,5)$. Beta diversity was taken as the only value to express the differences between the sub-sampling areas in each sample field, thus the number of beta diversity $(\beta=800 / 4)$ measurement was 200 .

Beta $(\beta)$ plant diversity for each field was specified using Whittaker's $\beta w$ index as given in formula below (Özkan, 2010; Özkan, 2016).

$$
\beta w=\left(\gamma / \alpha_{s}\right)-1
$$

In this formula, $\alpha_{s}$ stands for the average values of alpha diversity in each sub-sampling area within a sample field.

Beta values of plant species diversity for 200 sample fields that were calculated with the help of Past $2.17 \mathrm{c}$ software (Hammer et al., 2001) were stored in order to correlate with the climate variables for the same fields. Pearson correlation analysis was conducted in order to present the relationship between climate variables and beta diversity through SPSS package software program, and Start soft Statistica software was used to provide more graphical correlations (Türkbal, 1981; Ergün, 1995; SPSS, 2010; Ural and Kılıç, 2005).

\section{Results and Discussion}

A total of 103 woody plant species found in 800 subsampling areas in 200 sample fields was registered in the inventory. The species with the highest frequency are respectively Juniperus oxycedrus, Juniperus excelsa, Berberis crataegina, Astragalus nanus. The species with the least frequency are Astragalus micrancistrus, Calicotome villosa, Ephedramajorand Thymus spicata (Fig 1).

Two hundred beta values were calculated based on Whittaker's beta index. Pearson correlation analysis was performed to decipher the relationship between beta values and 19 climate variables. Pearson correlation analysis results are

Table 1: Climate variables and their codes

\begin{tabular}{|c|c|}
\hline Description of the climate variables & Codes of variables \\
\hline Annual mean temperature & $\mathrm{Bio1}^{*}$ \\
\hline Mean diurnal range (mean of monthly (max temp - min temp)) & $\mathrm{Bio} 2^{*}$ \\
\hline Isothermality & $\mathrm{Bio3}^{*}$ \\
\hline Temperature seasonality & $\mathrm{Bio}^{*}$ \\
\hline Max temperature of warmest month & Bio5* \\
\hline Min temperature of coldest month & $\mathrm{Bio6}^{*}$ \\
\hline Temperature annual range & $\mathrm{Bio} 7^{*}$ \\
\hline Mean temperature of wettest quarter & Bio8* \\
\hline Mean temperature of driest quarter & Bio9* \\
\hline Mean temperature of warmest quarter & Bio10* \\
\hline Mean temperature of coldest quarter & Bio11* \\
\hline Annual precipitation & Bio12* \\
\hline Precipitation of wettest month & Bio13* \\
\hline Precipitation of driest month & Bio14* \\
\hline Precipitation seasonality & Bio15* \\
\hline Precipitation of wettest quarter & Bio16* \\
\hline Precipitation of driest quarter & Bio17* \\
\hline Precipitation of warmest quarter & Bio18* \\
\hline Precipitation of coldest quarter & Bio19* \\
\hline
\end{tabular}

* The variable codes are the abbreviations used in www.worldclim.org webpage 

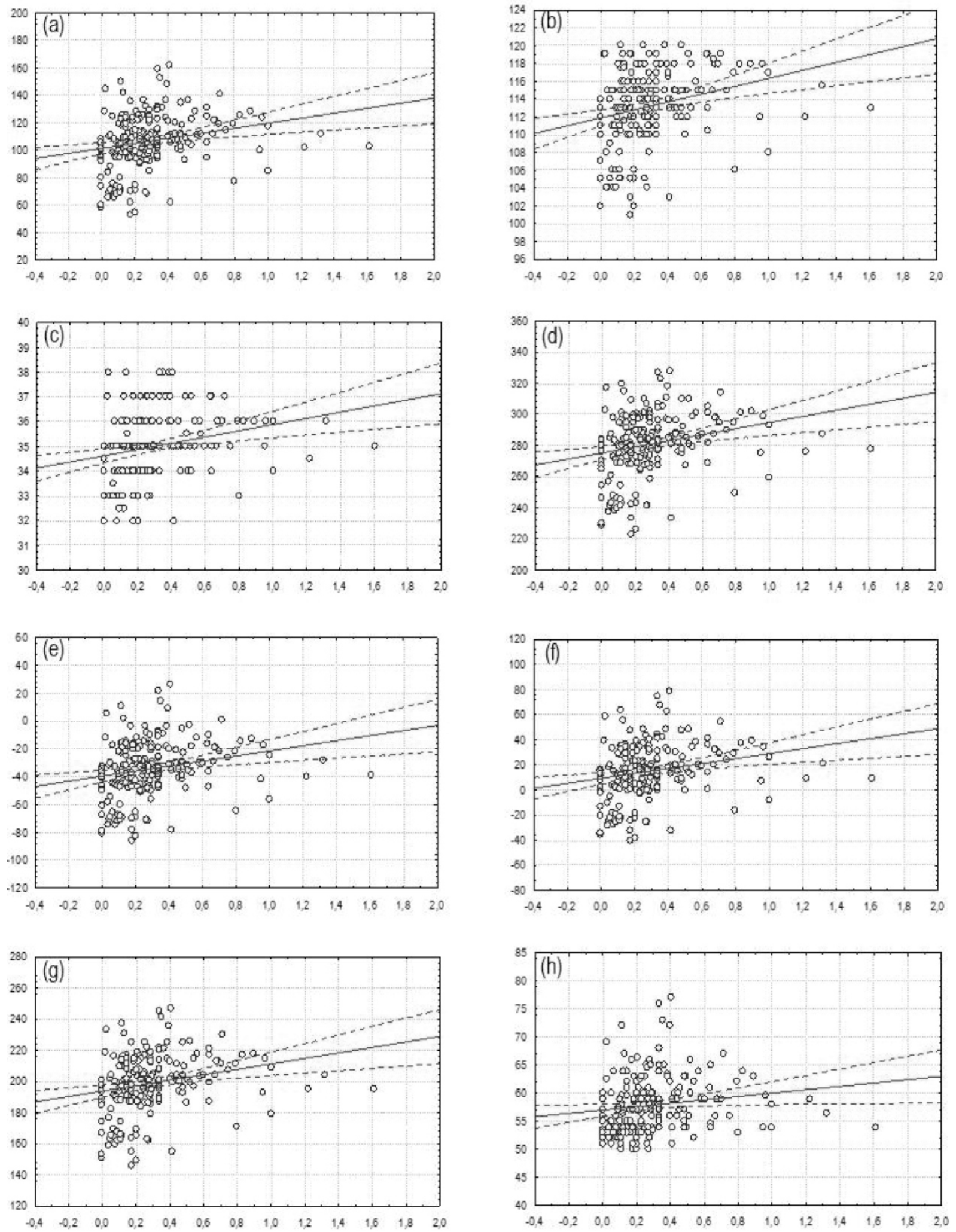

Fig. 2 : Distribution of beta plant diversity and climate changes with positive correlation ( ${ }^{*} 5 \%(p \leq 0,05)$ significance level) 

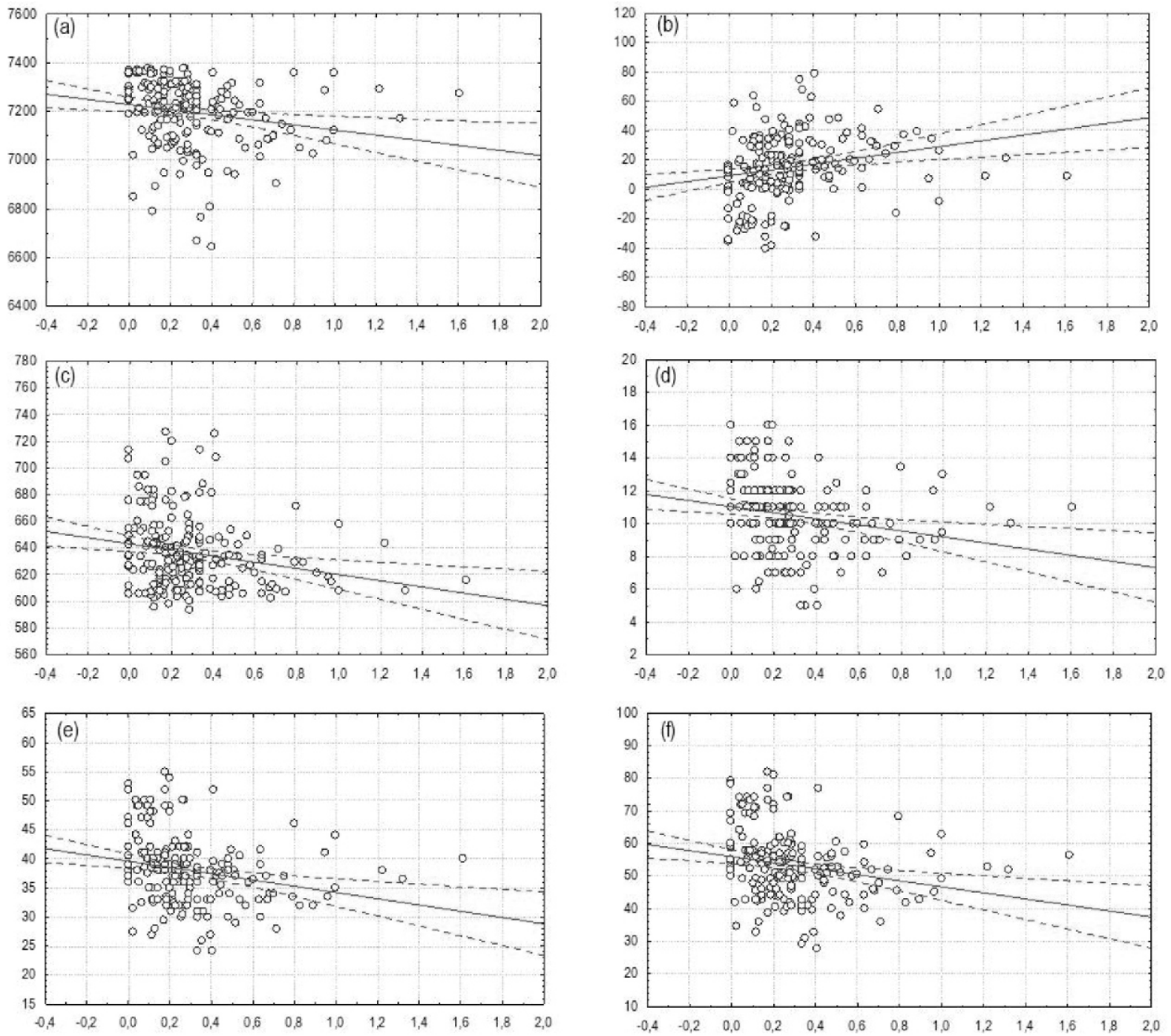

Fig. 3 : Distribution of beta plant diversity and climate changes with negative correlation

given in Table 2. From the results, it can be concluded that beta diversity is in positive correlation with the climate variables of Bio1, Bio2, Bio3, Bio5, Bio6, Bio8, Bio9 and Bio10 with a 1\% ( $\mathrm{p} \leq$ $0,0)$ significance level, while it is in negative correlation with the climate variables of Bio4, Bio11, Bio12, Bio14, Bio17 and Bio18 with a $1 \%(p \leq 0,0)$ significance level. In addition, a positive correlation between Bio15 climate variable and beta diversity with a $5 \%(p \leq 0,05)$ significance level was found. However, no correlation was found between Bio7, Bio13, Bio16 and Bio19 climate variables and beta diversity was found.

For studying the species diversity and its environment in an ecosystem, it is necessary to measure three diversity components, alpha diversity, beta diversity and gamma diversity. However, beta diversity is most important of all diversity components, because it expresses habitat differences in an ecosystem, which suggests that higher these differences are more living creature richness in that ecosystem. In this sense, determining the fields with beta-diversity conservation status is of great importance (Wilson and Shmida, 1984; Quianet al., 2005; Ricotta, 2007).

As a result of the analysis, a positive correlation between beta plant species diversity and 9 climate variables (Bio1, Bio2, Bio3, Bio5, Bio6, Bio8, Bio9, Bio10, Bio15) was found, negative correlation was found with 6 climate variables (Bio4, Bio11, Bio, 12, Bio14, Bio17, Bio18), and no correlation was found out with 4 climate variables (Bio7, Bio13, Bio16, Bio17).

The obtained relationships show that the average temperature increases by the beta diversity in the region. Similarly, beta diversity increased by increase in mean 
Table 2 : Correlation analysis results of beta plant diversity and climate variables

\begin{tabular}{llllll}
\hline Variable Code & Relationship coefficient & Significance level & Variable code & Relationship coefficient & Significance level \\
\hline Bio1 & $0,229^{* *}$ & 0,001 & Bio11 & $-0,369^{* *}$ & 0,000 \\
Bio2 & $0,259^{* *}$ & 0 & Bio12 & $-0,211^{* *}$ & 0,003 \\
Bio3 & $0,237^{* *}$ & 0,001 & Bio13 & 0,019 & 0,790 \\
Bio4 & $-0,188^{* *}$ & 0,008 & Bio14 & $-0,206^{* *}$ & 0,003 \\
Bio5 & $0,239^{* *}$ & 0,001 & Bio15 & $0,150^{*}$ & 0,034 \\
Bio6 & $0,226^{* *}$ & 0,001 & Bio16 & $-0,013$ & 0,852 \\
Bio7 & 0,134 & 0,058 & Bio17 & $-0,229^{* *}$ & 0,001 \\
Bio8 & $0,228^{* *}$ & 0,001 & Bio18 & $-0,225^{* *}$ & 0,001 \\
Bio9 & $0,231^{* *}$ & 0,001 & Bio19 & $-0,013$ & 0,852 \\
Bio10 & $0,234^{* *}$ & 0,001 & & & \\
\hline
\end{tabular}

temperature of wettest months. Considering the negative correlations, it can be suggested that beta diversity decreases in humid regions with higher precipitation.

Altitude in Kuyucak Mountain District varies in the range of 200-2200 m. With the increase in altitude, temperature decreases and precipitation increases, and this results in climate differences. This consequently leads to strong correlation between distribution of vegetation communities and altitude. While ponderosa plant communities exist at 200-1200 m altitude, Taurus cedar and larch plants occur at altitudes between 1200 and $2200 \mathrm{~m}$.

Structural variability of land, especially in the lower and middle mountainous part of Kuyucak Mountain District was higher compared to the higher parts. While climate effects beta diversity, structural variability of land had also influenced on it. Due to increase in humidity in the higher parts of the region, a diverse result was obtained regarding the expectations of higher beta diversity in these areas, and this is basically related to the high structural diversity of land especially in the middle and lower mountainous part of the region. In other words, structural variability of land in Kuyucak Mountain District affects beta plant diversity much more than climatic characteristics. Therefore, data related to the structural change of land and association with beta diversity are of high significance. Data can be collected about the structural variability of land based on the results of this study and further studies can be conducted about beta diversity.

As Kuyucak Mountain District has transitional climate features and has a mountainous structure, climatic characteristics of the region, the structural diversity of land, and other environmental variables have important roles on the distribution of plant species. Therefore, further studies can be conducted about other climatic variable in the region as well as other environmental variables in order to associate with beta diversity. Thus, potential distribution areas of the plant species and biodiversity components can be identified and mapped with the help of base maps for the area's habitat variables.

\section{Acknowledgments}

We acknowledge the Scientific and Technological Research Council of Turkey (TÜBITAK) which provided financial support to this project (PN:1130495) which entitled "Spatial Modeling of Woody Plant Diversity in the Kuyucak Mountain District".

\section{References}

DMi, Turkish State Meteorological Service. Report on evaluation of synoptic air conditioning and automatic station data between 1993-2011 (Numerical data), Ankara, 809 (2012).

Ergün, M.: Computer Statistics Applications in Scientific Researches, SPSS for Windows. January Publications, Ankara, p. 292(1995).

Hammer, $\varnothing .$, D.A.T. Harper and P.D. Ryan: Past: Paleontological statistics software package for education and data analysis. Palaeontologia Electronica, 4, (2001).

Hashemi, S.A.: Evaluating plant species diversity and physiographical factors in natural broad leaf forest. American J. Environ, 6, 20-25 (2010).

Hijmans, R.J., S.E. Cameron, J.L. Parra, P.G. Jones and A. Jarvis: Very high resolution interpolated climate surfaces for global land areas. Int. J. Climatol, 25, 1965-1978 (2005).

Hunter, M.J.: Benchmarks for managing ecosystems: Are human activities natural. Conservat. Biol., 10, 695-697 (1996).

Işık, D. and E. Ugurlu: Beta diversity on the plant communities. Celal Bayar University. J. Educ. Fac., 1, 154-171 (2011).

Kaya, Z.: Conservation Biology and Biodiversity. Forest and Hunting, Young Offset Printing, 4, 24-34 (2003).

Linder, H.P.: Plant diversity and endemism in sub-saharan tropical Africa. J. Biogeogr., 28, 169-182 (2001).

Mareno, C., I. Zuria, M. García-Zentono, G. Sánches-Rojas, I. Castellanos, M. Martínes-Morales and A. Rojas-Martínes: Trends in the measurement of alpha diversity in the last two decades. Interciencia, 31, 67-71 (2006).

Özcelik, H. and M. Korkmaz: Floristic analysis of the lakes region. National Symposium on Aksu Districts and Values, (2012).

Özkan, K.: Relationships between tree and scrub species diversity and physiographic site factors in Çariksaraylar site section groups, beyşehir watershed. Anad. Univer. J. Sci. Technol., 7, 157-166 (2006). 
Özkan, K.: Global climate change scenarios. J. Forest Eng., (2010).

Özkan, K. and S. Gülsoy: Ecological land classification and mapping based on vegetation-environment hierarchical analysis - A case study of Buldan Forest district. Turkey. Pol. J. Ecol., 58, 55-67 (2010).

Özkan, K. and H. Süel: Endemic Plant species in a Karstic Canyon (Mediterranean Region, Turkey): Relation to relief and vegetation diversity. Pol. J. Ecol., 56, 709-715 (2008).

Özkan, K.: How are biological diversity components measured? Süleyman Demirel University Publications of Forest Faculty, p. $142(2016)$

Pausas, J.G. and M.P. Austin: Patterns of plant species richness in relation to different environments: An Appraisal. J. Veget. Sci., 12, 153-166 (2001).

Quian, H., R. E. Ricklefs and P. S. White: Beta diversity of angiosperms in temperate floras of eastern Asia and eastern North America. Ecology Letters, 8, 15-22 (2005).

Ricotta, C.: Computing additive B-diversity from presence and absence scores: Acritique and alternative parameters. Theor. Popul. Biol.,
73, 244-249 (2007)

SPSS: Statistical Package for Windows. Version 13.0, Chicago, IL, USA: SPSS, Inc. (2010).

Thompson, I.D., B. Mackey, S. McNulty and A. Mosseler: Forest resilence, biodiversity and climate change. A synthesis of the biodiversity/resilence/stability relationships in forest ecosystemsSecretariat of the Convention on Biodiversity, Montreal, 43, pp. 6773 (2009).

Türkbal, A.: Scientific research methods and applied statistics. Ankara University, Publication Of Faculty Business (1981)

Ural, A. and I. Kilıç: Scientific research process and data analysis with SPSS. Detail Publishing. p. 339 (2005).

Whittaker, R.H.: Evolution and measurement of species diversity. Taxon, 21, 213-251 (1972).

Wilson, M.V. and A. Shmida: Measuring beta diversity with presenceabsence data. J. Ecol., 72, 1055-1064 (1984).

Zhao, C.M., W.L. Chen, Z.Q. Tian and Z.Q. Xie: Altitudinal pattern of plant species diversity in shennongjia mountains, Central China. $\mathrm{J}$. Integr. Plant. Biol., 47, 1431-1449 (2005). 